NBSIR 87-3652

\title{
Surveillance of Accredited Laboratories Under Procedures of the National Voluntary Laboratory Accreditation Program (NVLAP)
}

Harvey W. Berger

U.S. DEPARTMENT OF COMMERCE National Bureau of Standards

Associate Director of Industry and Standards

Gaithersburg, MD 20899

September 1987

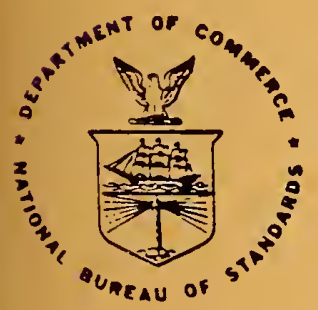

U.S. DEPARTMENT OF COMMERCE NATIONAL BUREAU OF STANDARDS 

NBSIR 87-3652

SURVEILLANCE OF ACCREDITED

LABORATORIES UNDER PROCEDURES OF THE

NATIONAL VOLUNTARY LABORATORY

ACCREDITATION PROGRAM (NVLAP)

Harvey W. Berger

U.S. DEPARTMENT OF COMMERCE

National Bureau of Standards

Associate Director of Industry

and Standards

Gaithersburg, MD 20899

September 1987

U.S. DEPARTMENT OF COMMERCE, Clarence J. Brown, Acting Secretary NATIONAL BUREAU OF STANDARDS, Ernest Ambler, Director 


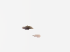


Surveillance of Accredited Laboratories Under Procedures of the National Voluntary Laboratory Accreditation Program (NVLAP)

by

Harvey W. Berger, Manager

Laboratory Accreditation

National Bureau of Standards

The National Bureau of Standards accredits testing laboratories that meet accreditation criteria, for specific test methods or types of tests, developed under the procedures of the National Voluntary Laboratory Accreditation Program (NVLAP). A laboratory which meets the specified NVLAP criteria is deemed to be "competent" to perform the test methods for which it is accredited.

An important issue which must concern all accrediting agencies, including NVLAP, is demonstration of the continued maintenance of a laboratory's competence. Has the laboratory continued to comply with the accreditation criteria a day, week, or six months after the initial determination of competence? The quality and reputation of any laboratory accreditation system relies, in large part, on the measures it takes to assure continuing compliance by a laboratory to all requisite conditions throughout the period of its accreditation.

Since NVLAP is not supported by appropriated funds, it is fully dependent on Eees paid by participating laboratories to carry out the functions necessary to confer and continue accreditation. The nature, extent, and frequency of on-site assessments, proficiency testing, and other incurring functions must be balanced against the ability and willingness of laboratories to bear those costs.

There is no practical means for completely assuring day-to-day compliance with accreditation criteria after initial accreditation. NVLAP therefore relies on three mechanisms, described below, to gather information about laboratory performance. They serve as a basis for a reasonable degree of confidence that an accredited laboratory continues to perform at an acceptable level with reference to the NVLAP criteria. 
1. Proficiency testing is a major element of NVLAP's accreditation process. Successful results of proficiency testing are a condition of continuing accreditation in all programs. The requirements of the programs vary, depending on opportunities, costs, difficulty in performing specific tests; availability of test artifacts, cooperation of other organizations (such as standards committees), and other external factors. Several programs call for two "rounds" of testing annually; some are implemented more frequently; others less frequently. The dosimetry program requires proficiency testing prior to initial accreditation and once every two years thereafter, but a testing sequence is performed over a 3 -month period.

The results of an individual laboratory's proficiency testing provide an indication of the laboratory's overall ability to carry out a specific test method. If a laboratory's performance is an outlier compared with the group mean, or if it fails to meet a pass/fail criterion, the precise nature of the testing problem cannot be pinpointed. However, unsatisfactory perforinance clearly indicates that the laboratory is not competent to perform the test method. If the causes of unsatisfactory proficiency testing can be easily determined and are corrected, NVLAP takes no further action with regard to the laboratory's accreditation. Failure to identify the causes, or inability to resolve related problems through discussion between NVAP and laboratory staff, necessitates special proficiency tests, a special on-site assessment geared particularly to resolving the testing problems, or suspension of the laboratory's accreditation for the pertinent test methods.

2. Regularly scheduled on-site assessments are performed biennially after initial accreditation. NVtAP uses technical experts, as peer assessors, who are very knowledgeable in the applicable fields of testing and have experience in testing and laboratory management. Assessors are assigned so that they do not visit the same laboratory twice in succession. Prior to a laboratory visit, NVLAP provides the assessor with copies of previous assessment reports, applications, proficiency testing results, and any correspondence relevant to the laboratory's testing performance. During regularly scheduled assessments, emphasis is placed on review of areas in which the laboratory had previous deficiencies or difficulties in proficiency testing.

NVLAP also performs monitoring visits on a random or opportunistic basis 
(e.g., when travelling for other purposes to a location near an accredited (laboratory), or to assure that a laboratory has resolved serious deficiencies or proficiency testing problems.

3. The laboratory's own quality assurance system is a reflection of its commitment to competent testing and good laboratory practices. Conscientious implementation, by the laboratory, of its own QA system is NVLAP's greatest assurance that the laboratory is performing quality testing on a day-to-day basis. NVLAP criteria address quality system requirements in both general and specific terms. NVLAP assessors carefully review quality assurance manuals and related documents; they evaluate management and staft use the manuals and their implementation of the QA system. The absence or inadequacy of quality system documentation constitutes a major deficiency which must be resolved before initial accreditation. Evidence that a laboratory is not fully implementing its own QA system may be grounds for suspension or termination of accreditation.

The community of testing laboratories and their clients is an informal mechanism that assists NVLAP in monitoring continuing compliance of laboratories with the criteria for accreditation. Laboratories inform NVLAP when their competitors make inappropriate claims or act in a manner which might be a violation of NVLAP criteria. These alleged violations most often relate to advertising, use of the NVLAP logo, and issuance of test reports implying product certification or approval. On occasion, test data reported by a NVLAP-accredited laboratory have been challenged by another laboratory. NVLAP has responded by carrying out appropriate reviews by technical experts and conducting investigations necessary to determine if laboratory testing competence was the underlying cause of the complaint.

NVLAP must continually strike a balance between actions to assure continued competence of participating laboratories and the costs of those actions. Participating laboratories must meet the attendant costs of accreditation. The program, therefore, tends to attract laboratories which are committed to maintaining their reputations for high quality testing. Experience has shown that after any significant technical or documentary deficiencies are identified during the initial on-site assessment, and they are resolved, the laboratories maintain an ongoing high level of compliance. Wide discrepancies 
in proficiency testing more often results from limitations in the test methods than from inadequate performance by the laboratories.

With the single exception of the dosimetry program, NVLAP grants accreditation on an annual basis. Yearly reaccreditation contributes significantly to the surveillance process since the submittal of an application by the laboratory affords NVLAP an opportunity to review administrative and technical information provided by the laboratory. Laboratory management attests, by signature, that it continues to be in compliance with the NVLAP accreditation criteria. The annual payment of fees is further affirmation of laboratory management's serious commitment to accreditation.

Laboratories that seek, gain, and maintain NVLAP accreditation highly value that accreditation. They insist that NVLAP conduct its programs to ensure that only highly qualified laboratories obtain accreditation and, with few exceptions, make sincere efforts to comply with the accreditation criteria. That attitude is the most reliable mechanism for assuring continuing competence of accredited laboratories. 
1. PUBLICATION OR REPORT NO.

NBSIR $87-3652$
2. Performing Organ. Report Nod 3. Publication Date

SEPTEMBER 1987

SHEET (See in struction s)

4. TITLE AND SUBTITLE

Survelliance of Accredited Laboratories Under Procedures of the

National Voluntary Laboratory Accreditation Program (NVLAP)

5. $A U T H Q R(S)$

Harvey W. Berger

6. PERFORMING ORGANIZATION (If joint or other than NBS, see instructions)

7. Contrace Grant No.

NATIONAL BUREAU OF STANDARDS

U.S. DEPARTMENT OF COMMERCE

GAITHERSBURG, MD 20899

9. SPONSORING ORGANIZATION NAME AND COMPLETE ADDRESS (Street。City。 Stote ZIP)

8. Type of Report \& Period Covered

10. SUPPLEMENTARY NOTES

Document describes a computer program; SF-185, FIPS Software Summary, is attached.

11. ABSTRACT (A 200-word or less foctual summory of most significont informotion. If document includes a significant bibliography or literoture survey. mention it here)

This paper describes mechanisms by which the National Voluntary

Laboratory Accreditation Program (NVLAP) seeks to assure continuing competence of accredited laboratories to perform specific test methods or types of tests. Surveillance of laboratories (defined as actions taken after initial

accreditation to ensure continued compliance with accreditation criteria) is achieved through proficiency testing, on-site assessments, and emphasis on the laboratory's own quality assurance system.

12. KEY WORDS (Six to twelve entries; alphabetical order: capitalize only proper nomes; and seporote key words by semicolons) acereditation; as3вз3ment; laboratory accreditation; proficiency testing: quality assurance; surveillance

13. AVAILABILITY

$X$ Unlimited

For Official Distribution. Do Not Release to NTIS

$\square$ Order From Superintendent of Documents, U.S. Government Printing Office, Washington, D.C. 20402.

X Order From National Technical Information Service (NTIS), Springfield, VA. 2216I

14. NO. OF

PRINTED PAGES

7

15. Price

$\$ 9.95$ 




\section{IR 87-3653}

\section{RESTRICTED}

\section{UNAVAILABLE FOR BINDING}




\section{IR 87-3654}

\section{CANCELLED 12/17/87}

\section{UNAVAILABLE FOR BINDING}





\section{Center for Electronics and Electrical Engineering}
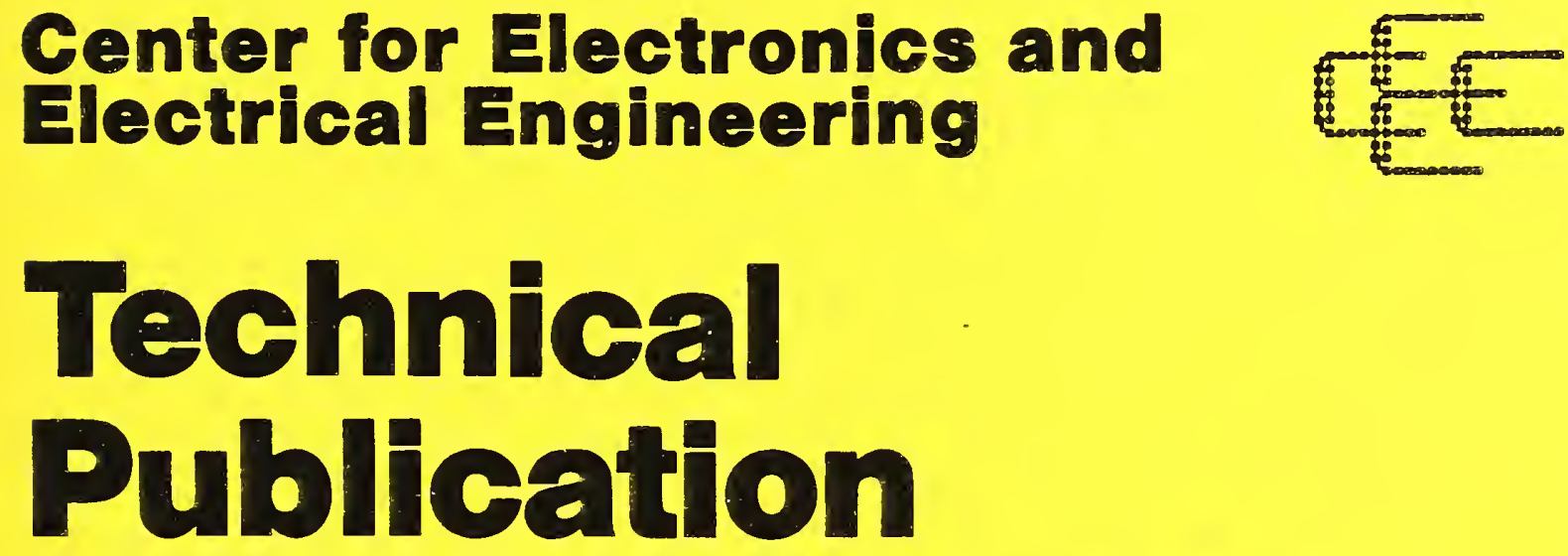

Announcements

\section{Covering Center Programs,} January to March 1987, with 1987 CEEE Events Calendar

August 1987

U.S. Department of Commerce

National Bureau of Standards

National Engineering Laboratory

Gaithersburg, Maryland 20899

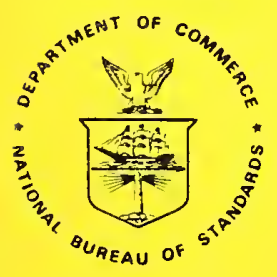


This is the twelfth issue of a quarterly publication providing information on the technical work of the National Bureau of Standards Center for Electronics and Electrical Engineering. This issue of the CEEE Technical Publication Announcements covers the first quarter of calendar year 1987.

Drganization of Bulletin: This issue contains citations and abstracts for center papers published in the quarter. Entries are arranged by technical topic as identitied in the table of contents and alphabetically by first author within each topic. Following each abstract is the name and telephone number of the individual to contact for more information on the topic (usually the first author). This issue also includes a calendar of Center conferences and workshops planned for calendar year 1987 , some preliminary events for 1988, and a list of sponsors of the work.

Center for Electronics and Electrical Engineering: Center programs provide national reference standards, measurement methods, supporting theory and data, and traceabili ty to national standards.

The metrological products of these programs aid economic growth by promoting equity and etficiency in the marketplace, by removing metrological barriers to improved productivity and innovation, by increasing U.S. competitiveness in international markets through facilitation of compliance with international agreements, and by providing technical bases for the development of voluntary standards for domestic and international trade. These metrological products also aid in the development of rational regulatory policy and promote efficient functioning of technical programs of the Government.

The work of the Center is divided into two major programs: the semiconductor Technology Proyram, carried out by the semiconductor Electronics Division in Gaithersburg, ML, and the Signals and Systems Metrology Program, carried out by the Electrosystems Division in Gaithersburg and the Electromagnetic Fields and Electromagnetic Technology Divisions in Boulder, CO. See the table of contents on the opposite page tor identification of the topics covered by each program, as represented in this issue. Key contacts in the center are given on the back cover; readers are encouraged to contact any of these individuals for further information.

Center sponsors: The Center programs are sponsored by the National Bureau of Standaras and a number of other organizations, in both the Federal and private sectors; these are identified on page 16.

Note on Publication Lists: Guides to earlier as well as recent work are the publicatlon lists covering the work of each division. These lists are revised and reissuec on an approximately annual basis and are available from the originating division. The current set is identified in the Additional Information section, page 14. 


\section{TABLE OF CONTENTS}

INTRODUCTION • • • • • • • • • • • • • • • • $\bullet$ inside front cover

SEMICONDUCTOR TECHNOLOGY PROGRAM

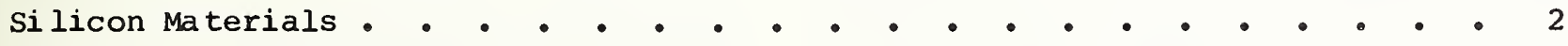

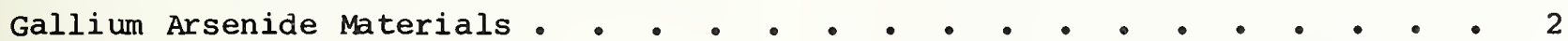

Dimensional Metrology - • • • • • • • • • • • • • • • • • 3

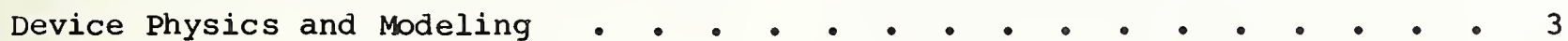

FAST SIGNAL ACQUISITION, PROCESSING, \& TRANSMISSION • • • • • • • • •

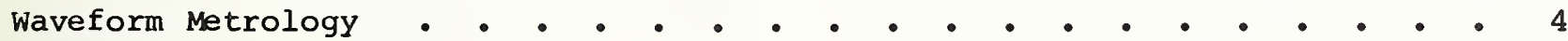

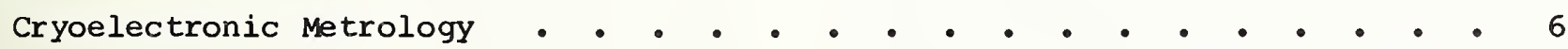

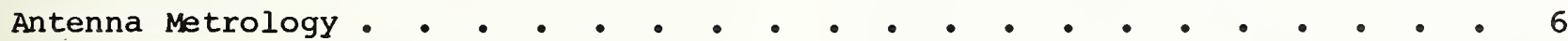

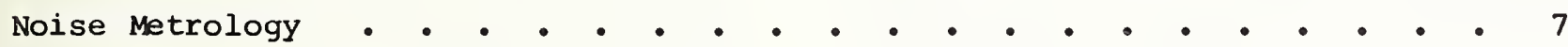

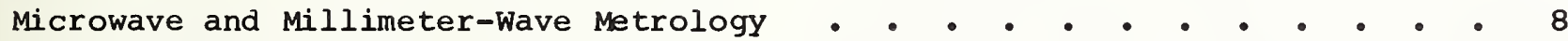

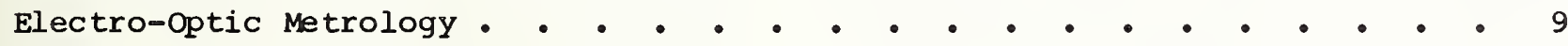

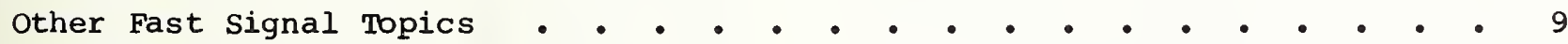

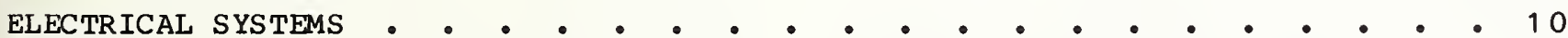

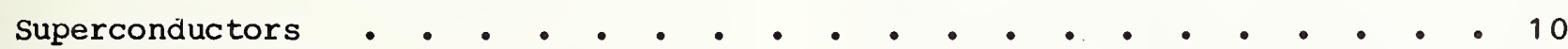

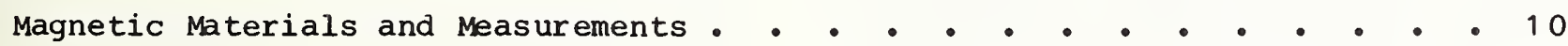

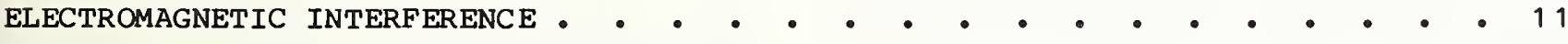

Radiated Electromagnetic Interference $\quad$ - $\quad$ - . . . . . . . . . 11

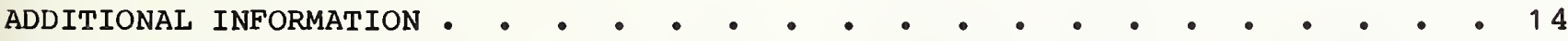
1987 CEEE CALENDAR • • • • • • • • • • • • • • • • • • • . 15

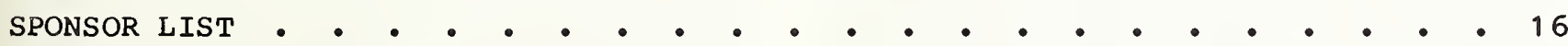
KEY CONTACTS IN CENTER, CENTER ORGANIZATION • • • • • • • • • • back cover 


\section{STMICONDUCTOR TECHNOLOGY}

\section{Silicon Materials}

Ehrstein, J. R., Spreading Resistance Measurements - An Overview, Emerging Semiconductor Technology, ASTM STP 960, D.C. Gupta and P.H. Langer, eds ., pp. 453-479 (American Society for Testing and Materials, 1987).

Spreading resistance is the most versatile electrical technique for characterizing depth profiles in silicon. However, it is being increasingly challenged as an analytical method by shrinking device geometries. Consequently, refinement of such aspects as probe conditioning, sample preparation and bevel angle measurement is needed, and traditional practice regarding calibration, algorithms and profile interpretation must be reexamined. Based on examples drawn from the author's work, multilaboratory experiments, and recent literature to illustrate and discuss these topics, this paper will attempt to sumarize the current status of the measurement and its interpretation showing both strong points and apparent lime tations.

[Contact: James R. Ehrstein, (301)

97b-2060]

Gladden, W. K., and Baghdadi, A., Free Carrier Absorption and Interstitial oxygen Measurements, Emerging Semiconductor Technology, ASTM STP 960, D.C. Gupta and P.H. Langer, eds., pp. 353-364 (American Society for Testing and Materials, 1987).

The infrared (IR) absorption of both $n-$ and $\mathrm{p}$-type silicon samples were measured over the concentration range $\sim 10^{15} \mathrm{~cm}^{-3}$ to $10^{17} \mathrm{~cm}^{-3}$. The free carrier absorption exhibited a power-law dependence with wavenumber. The data were fit to a logarithmic function with this dependence, and these results were applied to the determination of the baseline from which to compute the corrected net IR absorption at $1107 \mathrm{~cm}^{-1}$ due to inter- stitial oxygen. Application of this correction for the free carrier absorption results in an improvement of 3\%-30\% in the accuracy of the oxygen content determination at concentrations above $10^{16}$ atoms $/ \mathrm{cm}^{3}$.

[Contact: Aslan Baghdadi, (301)

975-2062]

\section{Gallium Arsenide Materials}

Bouldin, C.E., Forman, R.A., and Bell, M.I., Conversion Yield ExAFS Measurements of Ion-Damaged GaAs, Physics Review B, Vol. 35, No. 3, pp. 1429-1432 (15 January 1987).

Extended $\mathrm{x}$-ray absorption fine structure (EXAFS) measurements of ion-implanted GaAs have been made using conversion electron detection. This total electron yield detection technique (termed CEEXAFS) allows near-surface sensitivity with a sampling depth of 700 to $1000 \AA$. Measurements of the $\mathrm{Ga}$ absorption edge show that implantation of $10^{16} \mathrm{~cm}^{-2}$ of $\mathrm{Zn}$ ions at $180 \mathrm{KeV}$ into GaAs produces heavy lattice damage (amorphization) to a depth of about 700 to $900 \AA$. After rapid thermal annealing, the amorphous layer is found to be recrystallized and structurally indistinguishable from unimplanted material. The sampling depth of CEEXAFS has been measured for the first time, using standards with known depth dependent structure. The CEEXAFS technique greatly reduces Bragg peak contamination of the EXAFS signal from single crystal materials, and allows measurement of a variety of samples which cannot be fabricated as thin layers for conventional transmission or fluorescence EXAFS measurements. The method permits examination of the local environment of host atoms (in this case Ga) in the near surface region without interference from the underlying bulk and without the distortions found in fluorescence EXAFS measurements of concentrated samples.

[Contact: Charles E. Bouldin, (301) 975-2046] 


\section{Dimensional Metrology}

\section{Larrabee, R.D., submicrometer Optical} and SEM Linewidth Metrology, Proceedings of the 1987 Measurement Science Conterence, Irvine, California, January 29-30, 1987, pp. V-D(1)-V-D(10).

The feature sizes on modern integrated circults are presently taxing the ability of visible-light optical systems to perform the necessary dimensional measurements required during their production. With the shrinking of feature dimensions to the micrometer and submicrometer level, diffraction and finite wavelength become the limitations of existing optical systems. In an effort to overcome these limitations, metrology systems based on the scanning electron microscope (SEM) have appeared and are often assumed to be the panacea of all the problems and the limitations of existing optical systems. In response to the application of the SEM to these problems, new optical systems have appeared including ultraviolet and laser scanning systems. This paper takes a critical look at the basic optical and $S E M$ metrologies, outlines the program at the National Bureau of standards to provide micrometer and submicrometer feature-size standards for both technologies, and discusses what can be done in practice until suitable standards become available.

[Contact: Robert D. Larrabee, (301) 975-2298]

Nyyssonen, D., A Practical Method for Edge Detection and Focusing for winewidth Measurements on Wafers, Optical Engineering, Vol. 26, No. 1, pp. 081-085 (January 1987).

Lack of precision and accuracy of inprocess critical dimension (CD) measurements of linewidth continues to be a serious problem at micrometer and submicrometer aimensions. Even with highly repeatable optical linewidth measurement systems, variable "offsets" or errors have been shown to occur with changes in process variables such as thickness of the patterned layer and sublayers and changes in the indices of refraction of the materials. All of these variations result in a change in the optical phase difference that occurs on reflection at the line edge and, therefore, result in changes in the structure of the optical image. Although an accurate coherent optical edge-detection method has been developed, it requires accurate knowledge of this phase difference, which is not always possible in $C D$ measurements. This paper proposes a new dual-threshold method for edge detection and focusing, based on image theory, which can be adapted to most optical microscope based measurement systems. It does not require knowledge of the phase discontinuity at the line edge. The accuracy of this criterion is compared to two more widely used criteria, (1) the minimum and (2) 508 threshold, and it is concluded that, when the phase difference is unknown and varies with normal processing, the new dual-threshold method is the superior method.

[Contact: Robert L. Larrabee, (301)

975-2298]

Device Physics \& Modeling

Albers, J., Monte Carlo Calculation of Primary Rinematic Rnock-On in SIMS, Emerging Semiconductor Technology, ASTM STP 960, D.C. Gupta and P.H. Langer, eds., pp. 535-557 (American Society for Testing and Materials, 1987).

Secondary Ion Mass Spectrometry (SIMS) occupies a central position in atomic profiling of semiconductor device structures. One of the possibilities for distortion of the profiles is the phenomenon of knock-on, in which the incident sputtering ion transfers enough kinetic energy to the impurity atoms to push them deeper into the material before they can be sputtered and counted. The effects of sputtering and primary kinematic knock-on are investigated by means of a Monte carlo code previously used to study ion implantation processes. In particular, the dependence of the primary kinematic knock-on on the 


\section{Device Physics \& Modeling (con'd.)}

mass and energy of the sputtering ion as well as the mass of the impurity atom are presented.

[Contact: John Albers, (301) 975-2075]

Albers, J., Some Aspects of Spreading Resistance Profile Analysis, Energing Semiconductor Technology, ASTM STP 960, D.C. Gupta and P.H. Langer, eds., pp. 480-501 (American Society for Testing and Materials, 1987).

The calculation of resistivity profiles (and carrier density profiles) from spreading resistance requires the use of a correction factor. The present status of the calculation of the correction factor based upon the Schumann and Gardner multilayer solution of Laplace's equation is reviewed and discussed. Recent calculations of carrier densities from atomic densities are also discussed. In particular, the numerical solutions of the semiconductor equations are reviewed, and their implications in the interpretation of spreading resistance measurements for profiling shallow layers are presented. The limitations of the multilayer Laplace equation analysis of spreading resistance in VLSI profiling are also discussed.

[Contact: John Albers, (301) 975-2075]

Marchiando, J.F., and Albers, J., Effects of Ion-Implantation Damage on Two-Dimensional Boron Diffusion in Silicon, Journal of Applied Physics, vol. 61, No. 4, pp. 1380-1391 (15 February 1987).

Well-defined control of boron implanted in silicon during a high-temperature short-time anneal is important in calculation of shallow $\mathrm{p}-\mathrm{n}$ junction profiles in metal oxide-semiconductor field-eftect transistors (MOSFETs). During an anneal, boron may exhibit enhanced aiftusion lasting about a second. Here, displacement damage is removed largely by release and condensation of single vacancies, which enhance the boron diftusion via the charged vacancy mechanism. Model 2-D distributions of boron and displacement damage implanted near a mask edge are used to calculate the redistribution of boron resulting from a seven-second-anneal. Boron redistributes further into the bulk, while leaving the channel length unaffected. The redistribution agrees favorably with that reported in the li terature.

[Contact: Jay F. Marchiando, (301) 975-2088]

FAST SIGHAL ACQUISITION, PROCESSING, AND TRANSMISSION

\section{Waveform Metrology}

Adair, R.T., Ehret, R.L., and Livingston, E.M., Measurement of RP Signal Generator Phase Noise Using a OneGenerator Delay-Iine Method, IEEE Transactions on Instrumentation and Measurement, Vol. IM-35, No. 4, pp. 496-502 (December 1986).

A technique is described which utilizes a single generator and a delay line for the measurement of frequency-domain phase noise in synthesized signal generators. Terms are defined and equations developed for theory and calculations of normalized phase-noise sideband power in a $1-\mathrm{Hz}$ bandwidth offset $20 \mathrm{kHz}$ from signal frequencies of interest. The system described covers the range from 0.45 to $2000 \mathrm{MHz}$. The function and contribution of each component in the measurement system is presented. Advantages of this method are discussed and a brief error analysis is given.

[Contact: Robert T. Adair, (303)

497-3461]

Kuffel, J., Malewski, R.A., van Heeswijk, R., and Lawton, R.A., Dynamic Performance of Digital Recorders Used for Monitoring High-Voltage Impulse Tests, IEEE Transactions on Instrumentation and Measurement, Vol. IM-35, No. 4, pp. 591-595 (December 1986). 
Waveform Metrology (cont'd.)

Frequency- and time-domain characteristics of digital transient recorders (in short, digitizers) are discussed in order to establish the requirements on digitizers used for high-voltage testing. Results of an experimental study performed on a 200-MHz 8-bit digitizer are presented and related to the design teatures of this instrument. The inherent design characteristics and their influence on the digitizer dynamic performance are analyzed in view of simulation of the digitizer through a computer model.

[Contact: Robert A. Lawton, (303)

497-3339]

Nahnan, N.S., Status and Future Directions of Picosecond Domain Waveform Measurements, Time-Domain Measurements in Electromagnetics, E.K. Miller, ed., Chapter 2 (Van Nostrand Reinhold Co., New York, NY, 1986), pp. 45-71.

The main purpose of this chapter is to (1) summarize the present-day capability in time-domain measurements for pulses or transient signals whose shape (evolution with time) occurs on a time scale of the order of picoseconds, and (2) offer some opinions as to the future directions of electrical and optical picosecond-domain pulse waveform measurements. Consequently, the techniques and other data presented here are limited to those suitable for such fast signals. For example, all of the methods cited recognize that the signal-circuit interconnections or transmission paths in devices and in instrumentation are distributed or wave-guiding in nature.

The review of the state of the art of picosecond time-domain waveform measurements presented here includes measurements in both the electrical (dc through $\mathrm{mm}$ waves, etc.) the optical regions (infrared through visible, etc.) of the electromagnetic spectrum. This review is the latest edition of a series of reviews on high-speed pulse measurements compiled by the author commencing in 1967; specifically, this review updates the 1983 review. The significance of the Institute of Electrical and Electronic Engineers (IEEE) Pulse Standards 181 and 194 and of the identical International Electrotechnical Commission (IEC) Standards 469-1 and 649-2 is discussed briefly. The classification of time-domain measurements from the 1978 review is summarized and augmented with basic instrumentation block diagrams. The present-day capabilities are presented via temporal resolution state-ofthe-art charts using the 1978 format. For the reader's convenience, the 1978 charts are reproduced here, along with charts that show only those changes that have occurred since 1978. The references cited in all of the chart entries are contained in the list of references.

[Contact: Ramon C. Baird (303)

497-3301]

Oldham, N.M., Techniques and Instruments for Automated Electrical Measurements, MAPAN, Journal of Me trology Society of India, Vol. 1, No. 1, pp. 25-27 (1986).

A summary of previous developments in the field of automated electrical measurements is presented.

[Contact: N. Michael Oldham, (301) 975-2408]

Schoenwetter, H.K., Flach, D.R., Souders, T.M., and Bell, B.A., A precision Programmable step Generator for Use in Automated Test Systems, NBS Technical Note 1230 (December 1986).

A precision voltage step generator has been designed for use in automated systems to test the dynamic response of waveform recorders and other instruments. The programmable pulse parameters include transition polarity, pulse length, and repetition rate. The initial and final levels of voltage steps are each programmable within the range of $\pm 1 \mathrm{~V}$ for a 50- $\Omega$ termination and 
Waveform Metrology (cont'd.)

within $\pm 5 \mathrm{~V}$ for a high impeaance load. Voltage steps within these ranges settle to within $\pm 0.02 \%$ of full scale range in less than 22 and 26 ns, respectively, for small load capacitance. The corresponding transition durations are approximately 6 and 7 ns.

[Contact: Howard K. Schoenwetter, (301) 975-2414]

\section{Cryoelectronic Metrology}

McDonald, D.G., High Accuracy in
Physics, Science, p. 829 (August 22,
$(986)$.

Phillp Abelson, in an editorial in Science, reviews the National Research Council report "Physics Through the 1990s" and writes "Of all the quantities in physics, time is by far the most accurately measured." I argue that the Josephson effect has comparable accuracy.

[Contact: Donald G. McDonald, (303) 497-5113]

Muhlfelder, B., Beall, J.A., Cromar, M.W., and Ono, R.H., Very Low Noise, Tightly Coupled, dc sQUID Amplifiers, Applied Physics Letters, Vol. 49, No. 17, October 27, 1986, pp. 1118-1120.

We have fabricated and tested thin-film, niobium edge junction, double transformer, ac superconducting quantum interference devices (SQUIDs) that were stable under room-temperature storage and thermal cycling and that had very good noise performance. The input inductance, approximately $1.7 \mu \mathrm{H}$, was large enough to tacilitate good matching to many experiments. When the SQUID was operated as a small-signal amplifier, the ininimum detectable energy per unit bandwidth $\left(\mathrm{S}_{\mathrm{e}}\right)$ was $5 \times 10^{-33} \mathrm{~J} / \mathrm{Hz}$ at $100 \mathrm{kHz}$, referred to the SQUID loop (uncoupled). The minimum detectable energy per unit bandwidth was $1.8 \times$ $10^{-31} \mathrm{~J} / \mathrm{Hz}$ at $100 \mathrm{kHz}$, referred to the input coil. The SQuIDs had good characteristics for flux-locked operation since the small signal $\mathrm{S}_{e}$ was low over a substantial range of bias current and magnetic flux. For operations in a flux-locked feedback circuit, $S_{e}$ was 6 $\times 10^{-32} \mathrm{~J} / \mathrm{Hz}$ at $1 \mathrm{kHz}$.

[Contact: James T. Beall, (303) 497-5989]

\section{Antenna Metrology}

Baird, R.C., Daywitt, W.C., Newell, A.C., Perera, S., Repjar, A.G., Wait, D.F., and Estin, A.J., Calibration Requirements for EHIF Satellite Communication systems, NBSIR 86-3058 (October 1986).

The calibration and measurement support requirements of millimeter-wave satellite systems such as MILSTAR have been investigated. Needs for measurements on satellite systems are reviewed. An overview of the various means available for calibrating antenna gain, one of the key measurements that needs to be accurately accomplished, is presented. Essentially three new measurement problems arise because of operating in the upper SHF and EHF frequency ranges. First, without adequate methods to measure the atmospheric loss, the accuracy of effective isotropic radiated power (EIRP) measurements in the 20 to $45 \mathrm{GHz}$ range can be no better than 0.5 $\mathrm{dB}$ to $3 \mathrm{~dB}$ (depending on frequency and antenna elevation angle), which is inadequate for MILSTAR requirements. second, stanāards and measurement support services are not presently available from the National Bureau of Standards and are needed to support millimeter-wave antenna gain and thermal noise measurements. Third, if the sun and/or moon are to be used for measuring the earth terminal $G / T$, earth terminal antenna gain, or satellite EIRP in the millimeter region, they need to be appropriately cnaracterized at those frequencies.

[Contact: Ramon C. Baird, (303) 497-3301]

Hill, D.A., Far-Field Transient Response of an Antenna from Near-Field 
Antenna Metrology (cont'd.)

Data, NBSIR 86-3063 (December 1986).

A theoretical basis for calculating the transient far-field response of an antenna trom planar near-field data in either the time domain or the frequency domain has been developed. A double integral must be evaluated if we begin with time-domain data, but a triple integral must be evaluated if we begin with trequency-domain data. However, the Irequency-domain integrals are in a form that is suitable for three-dimensional fast Fourier transform. Two idealized examples are studied, and identical results are obtained starting with trequency-domain or time-domain data. The main practical difficulty in determining the transient response is the large number of near-field samples that are required. If data are taken at only a few near-field points, then the singularity expansion method presents a possible method of determining the complex resonances of the antenna under test.

[Contact: David A. Hill, (303) 497-3472]

Hill, D.A., out-of-Band Response of Reflector Antennas, IEEE Transactions on Electromagnetic Compatibility, Vol. EMC-28, No. 2, pp. 80-89 (May 1986). [This paper includes Sections 1 through 3 and Appendix A of NBSIR 85-3021, April 1985.]

The response of reflector antennas to out-of-band frequencies has been analyzed using physical optics. A simple approximate expression has been obtained for the effective aperture, and this expression yields both the receiving pattern and the frequency dependence of the on-axis gain. The theory has been compared with published out-of-band measurements, and the pattern agreement is good, but the measured gain falls below the theory. This discrepancy is caused by mismatch loss in the coax-towaveguide adapter.

[Contact: David A. Hill, (303)

497-3472]
Muth, L.A., Displacement Errors in Antenna Near-Field Measurements and Their Effect on the Far Field, NBS Te chnical No te 1306 (October 1986).

The effects of probe displacement errors in the near-field measurement procedure on the far-field spectrum are studied. Expressions are derived for the displacement error functions that maximize the fractional error in the spectrum both for the on-axis and off-axis directions. Planar $\mathrm{x}-\mathrm{y}$ and $z$-displacement errors are studied first, and the results generalized to position errors in cylindrical and spherical scanning. Near-field models are used to obtain order-of-magnitude estimates for the fractional error as a function of relevant scale lengths of the near field, defined as the lengths over which significant variations occur.

[Contact: Lorant A. Muth, (303)

497-3603]

Noise Metrology

Baird, R.C., Daywitt, W.C., Newell, A.C., Perera, S., Repjar, A.G., Wait, D.F., and Estin, A.J., Calibration Requirements for EHIF Satellite Communication systems, NBSIR 86-3058 (October 1986).

The calibration and measurement support requirements of millimeter-wave satellite systems such as MILSTAR have been investigated. Needs for measurements on satellite systems are reviewed. An overview of the various means available for calibrating antenna gain, one of the key measurements that needs to be accurately accomplished, is presented. Essentially three new measurement problems arise because of operating in the upper SHF and EHF frequency ranges. First, without adequate methods to measure the atmospheric loss, the accuracy of effective isotropic radiated power (EIRP) measurements in the 20 to $45 \mathrm{GHz}$ range can be no better than 0.5 $\mathrm{dB}$ to $3 \mathrm{~dB}$ (depending on frequency and antenna elevation angle), which is inadequate for MILSTAR requirements. 
Noise Metrology (cont'd.)

Second, standards and measurement support services are not presently available from the National Bureau of standards and are needed to support millimeter-wave antenna gain and thermal noise measurements. Third, if the sun and/or moon are to be used for measuring the earth terminal $G / T$, earth terminal antenna gain, or satellite EIRP in the milimeter region, they need to be appropriately characterized at those frequencies.

[Contact: Ramon C. Baird, (303)

497-3301]

Mlcrowave and Millimeter-Wave Metrology

Adair, R.T., Reeve, G.R., and Gatterer, L.E., Millimeter-Wave Standards: An Emerging Need, IEEE Transactions on Instrumentation and Measurement, Vol. IM-35, No. 4, pp. 376-382 (December $1986)$.

Several technology surveys concerning millimeter-wave (MMW) measurement needs and capabilities have been conducted by the National Bureau of standards (NBS), Boulder Laboratories, and others. The results of some of these studies are summarized. Current MMW standards and calibration capabilities at NBS are reviewed. The lack of national standards in certain frequency bands may lead to problems with specification, acceptance testing, and calibration of some components and systems.

[Contact: Robert T. Adair, (303)

497-3461]

Ginley, R.A., and Allred, C.M., 1.25 $\mathrm{MHz}$ Attenuation Measurement System. IEEE Transactions on Instrumentation and Measurement, Vol. IM-35, No. 4, pp. 463-466 (December 1986).

A system has been developed to make highly accurate measurements of nominally $6-d B$ increments of attenuation at 1.25 $\mathrm{MHz}$. Inltial experiments indicate a typical systematic error of $5 \mu \mathrm{B}(1 \mu \mathrm{B}$ $=0.00001 \mathrm{~dB}$ ) with a resolution of $1 \mu \mathrm{B}$.
A special linearity measurement system (LMS) using NBS-constructed, linear tuned hybrids and power detectors has been used to determine the nonlinearity of a tuned 1.25-MHz power detector. This detector utilizes a single thermistor bead design with thermal isolation to obtain nearly linear tracking of a 4:1 change in input power. The nonlinear correction for this change, determined by the LMS, is on the order of $13 \mu \mathrm{B}$ for the detector presently in use. This calibrated detector and another of similar design are used in the attenuation measurement system to make power ratio measurements to determine the change in attenuation of the device under test. It is anticipated that changes of approximately 6 dB can be measured with initial insertion loss of up to $100 \mathrm{~dB}$ with an accuracy of $0.001 \mathrm{~dB}$. A special design consideration will be required for units used for calibration in order to keep mismatch errors from significantly degrading the accuracies estimated above.

[Contact: Ronald A. Ginley, (303)

497-3634]

Sequeira, H.B., and Yates, B.C., Approach for Evaluating Effects of WaIl Losses on Quarter-Wave Short-Circuit Impedance standards, IEEE Transactions on Microwave Theory and Techniques, Vol. MTT-33, No. 11, pp. 11061109 (November 1985)

The conservation of energy principle and first-order perturbation theory have been applied to obtain formulas for the physical lengths and reflection coefficient magnitudes of quarter-wave coaxial and rectangular waveguide shortcircuit impedance standards. The expressions for the physical lengths ensure zero phase angle at the mating interface when wall losses are present.

The method can be extended to include small dielectric and magnetic losses, and requires only knowledge of the lossfree solutions. It can also be applied to other waveguiding structures which support uncoupled modes. 
Microwave \& Millimeter-Wave (cont'd.)

[Contact: Billie C. Yates, (303) 497-3568]

\section{Electro-Optic Metrology}

Day, G.W., Hale, P.D., Deeter, M., Milner, T.E., Conrad, D., and Etzel, S.M., High Precision Electro-Optic and Magneto-optic Sensors for Power System Applications: Technical Feasibility, NBS Technical Note 1307 (March 1987).

The principles of electro-optic and magneto-optic sensors suitable for use in power system applications are reviewed with particular attention to the properties of materials and components that limit the precision of such sensors. Section topics include precision and accuracy in electro-optic and magneto-optic sensors; electro-optic and magneto-optic sensor configurations suitable for current and voltage measurements; critical evaluation of electro-optic sensor technology; critical evaluation of magneto-optic sensor technology; and suggested approaches to the development of high-precision optical current and voltage sensors. Data on a number of materials are collected and presented. For high-precision electrooptic sensors, it is recommended that crystals of the polar class having point symmetry $43 \mathrm{~m}$ be used. For highprecision magneto-optic sensors, a lead ylass with a low stress-optic coefficient is recommended. Choices for other components are also suggested. For both types of sensors, a precision of rouyhly \pm 18 over a $100^{\circ} \mathrm{C}$ temperature range should be attainable. To achieve a precision better than that, it will be necessary to use temperature compensation techniques, several of which are proposed and discussed.

[Contact: Gordon W. Lay, (303)

497-5204]

Other Fast Signal Topics

Hill, D.A., Electromagnetic wave
Propagation in an Asymetrical coal Seam, IEEE Transactions on Antennas and Propagation, Vol. AP-34, No. 2, pp. 244-247 (February 1986).

Electromagnetic wave propagation in a coal seam is analyzed for the case where the surrounding floor and roof rocks have differing electrical properties. Numerical results are presented for the attenuation rate and field distribution of the dominant mode. Even when the roof and floor conductivities are different, the vertical electric field and the horizontal magnetic field are the dominant components, and they are nearly constant within the coal seam. The results have application to mine communication and remote sensing of coal seams.

[Contact: David A. Hill, (303)

497-3472]

Hill, D.A., and wait, J.R., Anomalous Vertical Magnetic Field for Electromagnetic Induction in a Laterally Varying Thin Conductive Sheet, Radio Science, Vol. 21, No. 4, pp. 617-621 (JulyAugust 1986).

We employ a simple model to show how the natural electromagnetic field on the surface of the earth, which has a strong horizontal magnetic field component, can be converted to a significant vertical magnetic field at the surface. such a conversion mechanism will be caused by lateral variations of the subsurface conductivity structure. our idealized model is a thin conducting sheet with a periodic variation of the conductivitythickness product in one horizontal direction only.

[Contact: David A. Hill, (303)

497-3472]

Perrey, A.G., Bell, B.A., and Treado, M.J., Evaluation of Electronic Monitoring Devices, NBSIR 86-3501 (December 1986).

Electronic Monitoring Devices (EMDs) are used to monitor the presence of individuals within a given area who are respon- 
Other Fast Signal Topics (cont'd.)

sible to the criminal justice system but not confined to institutions. Several EMIIs were tested to measure operational characteristics such as operating fre quency, approximate range of operation, component capability, and tamper resistance. Tests were conducted in an open field, wooden residence, high rise metal bullding, and in a laboratory environment.

[Contact: Arnold G. Perrey, (301)

975-2782]

ELECTIRICAL SYSTEYS

\section{Superconductors}

Benson, R.G., Goldfarb, R.B., and Pittmann, E.S., Quench Circuit for Electronic Instruments Used with Superconducting Magnets, cryogenics, vol. 26 (Butterworth \& Co. Ltd., August/September 1986), pp.482-483.

A multifunction circuit is described that protects instruments connected or coupled to a superconducting magnet in the event of a quench.

[Contact: Ronald B. Goldfarb, (303)

497-3650]

Goldfarb, R.B, and Ekin, J.W., Hysteresis Losses in Fine-Filament InternalTin Superconductors, Cryogenics, Vol. 26 (Butterworth \& Co. Ltd., August/September 1986), pp. 478-481.

Hysteresis losses were measured on a series of fine-filament $\mathrm{Nb}_{3} \mathrm{Sn}$ superconductors made by the internal-tin process. Hysteresis was measured as a function of filament diameter and interfilament separation using a vibratingsample magnetometer in transverse magnetic tield. Losses were greater than expected compared to predictions of the critical-state model that expresses loss as a tunction of filament diameter. Micrographs of the reacted wire cross sections show some interfilament bridging for all wires. This bridging gives rise to effective filament diameters that are greater than actual diameters. The critical interfilament separation, above which the losses would be expected to follow the critical-state model, was determined.

[Contact: Ronald B. Goldfarb, (303)

497-3650]

Goldfarb, R.B., Internal Fields in Magnetic Materials and superconductors, cryogenics, vol. 26 (Butterworth \& $C_{0}$. Ltd. , August/September 1986), pp. 621-622.

This paper reviews some of the concepts needed for the correct analysis of magnetization data, both for magnetic materials and superconductors. Demagnetization factors, initial suceptibilities, and hysteresis losses are discussed. [Contact: Ronald B. Goldfarb, (303) 497-3650]

Magnetic Materials and Measurements

Capobianco, T.E., Moulder, J.C., and Fickett, F.R., Flaw Detection with a Magnetic Field Gradioneter, Proceedings of the Fifteenth Symposium on Nondestructive Evaluation, San Antonio, Texas, April 23-25, 1985, pp. 15-20.

When eddy currents are induced in a conductor, flaws deflect the eddy currents and perturb the associated electric and magnetic fielas. In conventional eddy current testing, the perturbed fields associated with a flaw are detected as a change in the impedance of the test coil used to induce the eddy currents. More direct methods for detecting and characterizing flaw-perturbed fields, both electric and magnetic, have also been developed. We describe a method for determining the normal component of the magnetic field gradient caused by a flaw. A novel feature of the measurement system is the use of a superconducting QUantum Interface Device (SQUID). The SQUID provides more sensitivity than conventional detection methods, and the possibility of calibration based on a fundamental physical quantity: the flux quantum. We 
Magnetic Materials, etc. (cont'd.)

report the results of a series of measurements on a fatigue crack and several manufactured defects in aluminum alloy specimens using this system. The effect of edge proximity compared to flaw signal and a figure of merit are also discussed.

[Contact: Thomas E. Capobianco, (303) $497-3141]$

Goldfarb, R.B., Internal Pields in Magnetic Materials and superconductors, Cryogenics, Vol. 26 (Butterworth \& $C_{0}$. Ltd., August/September 1986), pp. 621-622.

This paper reviews some of the concepts needed tor the correct analysis of magnetization data, both for magnetic materials and superconductors. Demagnetization tactors, initial suceptibilities, and hysteresis losses are discussed. [Contact: Ronald B. Goldfarb, (303) 497-3650]

\section{EI.BCTROMAGNETIC INTERPEREMCE}

Radiated Electromagnetic Interference

Adams, J.W., and Vanzura, E., Shielding fffectiveness Measurements of Plastics, EMC Technology, pp. 39-42 (September-October 1986).

Measurement of shielding effectiveness of plastic materials presents problems because of the insulating nature of many plastics. A method of making the measurements using a flanged coaxial holder overcomes these limitations. [Contact: John W. Adams, (303) 497-3328]

Bensema, W.D., Koepke, G.H., and Medley, H.W., Handbook for NBS Multisensor Automated IM Field Measurement System, NBSIR 86-3056 (October 1986).

A system is described that monitors and collects electromagnetic (EM) field strength information at five (optionally 10) locations simultaneously. The sys- tem has two modes of operation: (1) for sampling EM fields that are stationary for times of the order of $200 \mathrm{~ms}$, and (2) for sampling changing EM fields with a system resolution of $10 \mu \mathrm{s}$. Sensing elements for Mode 1 consist of three electrically short orthogonal dipoles mounted together, single dipole elements, or small loop antennas. Each element feeds a separate data input channel for a total of 15 (optionally 30) channels. Radiofrequency energy is converted to dc by a diode detector at each dipole. Mode 2 sensors are diode detectors driven by broadband antennas. Real-time system data processing includes calculation of field strength based on probe calibrations ard processing of resultant data to satisfy measurement goals.

[Contact: William D. Bensema, (303) 497-3465]

Cruz, J.E., and Larsen, E.B., Assessment of Errors for some Typical MIL STD-461/462 Types of Measurements, NBS Technical Note 1300 (October 1986).

This report deals with the instrumentation and equations for several systems used by the U.S. Army for electromagnetic compatibility (EMC) testing and calibrations. Most testing for MIL-STD$461 / 462$ is performed in a shielded enclosure (screenroom) rather than an open field site, which leads to uncertainty in the measurement of emissions from electronic equipment, or the susceptiblity of equipment to radiation. Assessment of error bounds by the National Bureau of Standards is covered in this report, and suggestions are given for improving the measurements.

Four areas of concern were studied as follows: (a) EM fields generated in a parallel-plate transmission line (stripline), (b) EM fields beneath a singlewire transmission line in a screenroom (longwire line), (c) determination of antenna factors for EMI antennas located in a screenroom, and (d) calibration of EMI receivers to measure broadband 
Radiated EMI (cont'd.)

impulsive signals. Most EMC antennas at NBS are calibrated at an open field site or in an anechoic chamber. This report presents antenna factors determined in a typical screenroom using the two-antenna method, and comparison with those determined at an open field site. The video pulse technique prescribed in MII-STD462 tor calibrating EMI receivers was also evaluated. Four different methods were tested for comparison with the MIL-STD approach. They are defined and discussed in this report.

[Contact: Jose E. Cruz, (303)

497-3763]

Jesch, R.L., A Survey of Triaxial and Mode-Stirred Techniques for Measuring the Shielding Effectiveness of Connectors and Cables, NBSIR 86-3060 (Oc tober 1986).

This report is the result of an extensive literature search conducted in the field of connectors and cables, with reference to radio-frequency leakage characteristics and capabilities for measuring shielding effectiveness of connectors and cables. The report reviews two measurement techniques for determining shielding effectiveness: the triaxial test technique that has been used for over 20 years and the mode-stirred test technique that recently has started to gain in popularity. From this survey, certain inferences are drawn about these techniques in terms of device configuration, frequency range, and ease of measurement and are presented in chart form for comparative purposes.

[Contact: Ramon L. Jesch, (303)

497-3496]

Kanda, M., Time-Domain Sensors and Radiators, Time-Domain Measurements in Electromagnetics, E.K. Miller, ed., Chapter 5 (Van Nostrand Reinhold Co., New York, NY, 1986), pp. 122-174.

The purpose of this chapter is to discuss various sensors and radiators com- monly used for time-domain antenna measurements. The sensors and radiators discussed here are passive analog devices that convert the electromagnetic quantity of interest to a voltage or current at their terminal ports. Moreover, they are primary standards in the sense that their transfer functions can be calculated from their geometries and are flat (frequency-independent) across a wide frequency range. One of the major requirements of these sensors and radiators is that the electromagnetic far field, for transmission or reception, be a replica or high-fidelity derivative of the original pulse.

Because of their usefulness in electricfield strength measurements, linear antennas nonuniformly and continuously loaded with resistance, or both resistance and capacitance, are discussed. Also, a conical antenna and an asymptotic conical antenna are examined from the standpoint of improved antenna characteristics. Various types of transverse electromagnetic (TEM) horns are considered for improved directivity, e.g., a conducting TEM horn and a resistively loaded TEM horn. For magneticfield strength measurements, a loop antenna with uniform resistive loading is discussed.

Section 5.1 discusses one of the important properties governing the transmitting and receiving transfer functions of an antenna. The frequency-domain and time-domain characteristics of the various electric- and magnetic-field sensors mentioned above are then covered in Secs. 5.2 and 5.3, respectively. [Contact: Motohisa Kanda, (303) 497-5320]

Kanda, M., and Wyss, J.C., Evaluation of off Axis Measurements Performed in an Anechoic Chamber, NBS Technical No te 1305 (October 1986).

The performance of a rectangular radiofrequency anechoic chamber is measured when the device under test is not on the center line of the launch antenna. An 


\section{Radiated EMI (cont'd.)}

electrically small field probe is repeatedly scanned longitudinally away from the launch antenna and into the chamber. With each scan, various parameters are changed, including: 1) horizontal and vertical position of the probe with respect to the center line of the launch antenna; 2) frequency; and 3) type of Launch antenna. With the probe located $1 \mathrm{~m}$ off the center line and scanning between 2 to 6 meters from the launch horn, the uncertainty due to being off the center line ranges from \pm 1 $\mathrm{dB}$ at $250 \mathrm{MHz}$ to $\pm 5.0 \mathrm{~dB}$ at $800 \mathrm{MHz}$ and above. If the probe is within $\pm 50 \mathrm{~cm}$ of center line, the uncertainty is no more than $\pm 1.5 \mathrm{~dB}$ at $800 \mathrm{MHz}$; and for $\pm 25 \mathrm{~cm}$ of center line, the uncertainty is further reduced to $\pm 0.5 \mathrm{~dB}$ at $800 \mathrm{MHz}$. [Contact: Motohisa Kanda, (303) 497-5320]

Ma, M.T., and Kanda, M., Electromagnetic compatibility and Interference Metrology, NBS Technical Note 1099 (July 1986).

The material included in this report is intended for a short course on electromagnetic compatibility/interference (EMC/EMI) metrology to be offered jointly by the staff of the Fields Characterization Group and the Interference Characterization Group of the Electromagnetic Fields Division. The purpose of this short course is to present a review of some of the radiated EMC/EMI measurement methods, to which the National Bureau of Standards (NBS) at Boulder, Colorado, has made significant contributions during the past two decades. The technical foundation for these methods, and interpretations of the measured results are emphasized, as well as strengths and limitations. The entire course is presented in nine chapters with the introductory part given as Chapter 1. The particular measurement topics to be covered are: i) open sites (Chapters 2 and 6), ii) transverse electromagnetic cells (Chapter 3), iii) techniques for measuring the electromag- netic shielding of materials (Chapter 4), iv) anechoic chambers (Chapter 5), and v) reverberating chambers (Chapter 8). In addition, since a small probe antenna plays an important role in some of the EMC/EMI measurements covered herein, a separate chapter on various probe systems developed at NBS is given in Chapter 7. Selected contemporary EMI topics such as the characterization and measurement of a complex EM environment, interferences in the form of out-of-band receptions to an antenna, and some conducted EMI problems are also briefly discussed (Chapter 9).

[Contact: Mark T. Ma, (303) 497-3800]

Randa, J., and Kanda, M., A Lattice Approach to Volumes Irradiated by Onknown Sources, NBS Technical Note 1303 (Oc tober 1986).

We suggest an approach to the characterization of electromagnetic environments irradiated by unknown sources. The approach is based on the numerical solution of Maxwell's equations subject to the constraints imposed by the measured values of the field at a small number of measurement points and by boundary conditions. A thorough examination is presented of two methods for the numerical solution. The examples attempted demonstrate the approach, but reveal that neither technique is fully successful. Possible future directions are suggested.

[A paper based on the contents of this Technical Note is scheduled for presentation at the seventh symposium and Technical Exhibition on EMC (Zurich, Switzerland, March 1987) under the title "A Lattice Approach to Environments Irradiated by Unknown Sources" and will appear in the proceedings of that symposium. A second paper based on this material has been submitted to the IEEE Transactions on Electromagnetic Compatibility with the title "A New Approach to Volumes Irradiated by Unknown Sources.]

[Contact: James P. Randa, (303) 497-3150] 


\section{Radiated EMI (cont'd.)}

Wilson, P.F., and Ma, M.T., Electromagnetic shielding Effectiveness: Measurement Techniques and Interpretations, 1986 IEEE Regional Conference \& Exhlbition on Electromagnetic Compatibility, Anaheim, California, February 6, 1986, pp. 1-14.

A material's shielding capability is generally measured in terms of insertion loss: the field reduction between a transmitter and a receiver achieved by introducing the shield material. Ambiguities often arise when one attempts to interpret specific measurement results. Insertion loss data depend not only on the shield material tested, but also on the measurement procedure and other parameters such as the antenna types (both transmitting and receiving) used and their positioning, the incident waveform and its wave impedance, transient effects, and the contact resistance between the test material and its mount, if any.

[Contact: Perry F. Wilson, (303)

497-3842]

Wilson, P.F., and Ma, M.T., Hethods for Measuring the Near-Field and FarField Shielding Effectiveness of Materials, Proceedings of the EMC Expo ' 86 Conference, Washington, D.C., June 16-19, 1986, pp. T281-T286.

Techniques for measuring the shielding effectiveness of materials are investigated. Specific approaches considered are coaxial transmission line holders and the use of a time-domain signal for simulating plane wave shielding performance, and the dual transverse electromagnetic (TEM) cell and an apertured TEM cell in a reverberation chamber for the simulation of near-field shielding capability. The advantages and limitations of each technique are summarized.

[Contact: Perry F. Wilson, (303)

497-3842]

ADDIPIONAT INFORMATION
Lists of Publications

Gibson, K. A., Page, J.M., and Miller, C.K.S., A Bibliography of the NBS Electronagnetic Fields Division-Publications, NBSIR 85-3040 (February 1986).

This bibliography lists publications of the National Bureau of Standards' Electromagnetic Fields Division for the period from January 1984 through september 1985, with selected earlier publications from the Division's predecessor organizations.

[Contact: Kathryn A. Gibson, (303)

497-3132]

Kline, K.E., and DeWeese, M.E., Metrology for Electromagnetic Technology: A Bibliography of NBS publications, NBSIR 86-3048 (June 1986).

This bibliography lists the publications of the personnel of the Electromagnetic Technology Division of NBS in the period from January 1970 through December 1985. A few earlier references that are directly related to the present work of the Division are included.

[Contact: Kathryn E. Kline, (303) 497-3678]

Palla, J.C., and Meiselman, B., Electrical and Electronic Metrology: A Bibliography of NBS Rlectrosystems Division Publications, NRS List of Publications 94 (January 1987).

This bibliography covers publications of the Electrosystems Division, center for Electronics and Electrical Engineering, NBS, and of its predecessor sections for the period January 1963 to January 1987. A brief description of the Division's technical program is given in the introduction.

[Contact: Jenny C. Palla, (301)

975-2220]

Walters, E.J., Semiconductor Measurement Technology: A Bibliography of NBS Publications for the Years 1962-1986, NBSIR 87-3522 (February 1987). 


\section{Lists of Publications (cont'd.)}

This bibliography contains reports of work performed at the National Bureau of standards in the field of semiconductor Measurement Technology in the period from 1962 through December 1986. An index by topic area and a list of authors are provided.

[Contact: E. Jane Walters, (301)

975-2050]

1987 CIEERE CALEIIDAR

September 22-25 (Boulder, CO)

Noise Measurement Seminar.

\section{CANCELED}

Oc tober 26-28 (Boulder, CO)

Symposium on Optical Materials for High Power. Lasers (Nineteenth Boulder Damage Symposium). This Symposium is cosponsored by the National Bureau of Standards, the American society for Testing and Materials, the Air Force Office of Scientific Research, the oftice of Naval Research, and the Defense Advanced Research Projects Agency and constitutes a principal forum for the exchange of information on the physics and technology of materials for highpower lasers.

Topics to be discussed include new materials, bulk damage phenomena, surface and thin-film damage, design considerations for high-power systems, and fundamental mechanisms of laser-induced damage. Proceedings of the symposium will be published (Note: The collection of Symposium proceedings contains information on optics for all aspects of high-power/high-energy lasers, including environmental degradation, durability, fabrication, material growth and deposition processes, and testing) - [Contact: Susie A. Rivera (303) 497-5342]

December 10-11 (Gaithersburg, MD)

\section{Power Semiconductor Devices Workshop.}

This workshop, sponsored jointly by IEEE and NBS, is intended to bring together for interactive participation those actively working in the field of power semiconductor devices. It will be held in conjunction with the 1987 IEEE International Electron Devices Meeting in Washington, DC. Four specific topic areas have been selected, based on the response to a questionnaire sent to over 200 power device researchers worldwide. They are: power and high voltage integrated circuits, discrete devices, device modeling, and packaging. Attendees are expected to be prepared to contribute to the development of responses to specific questions that arise in the context of the particular topic areas; a final schedule identifying the topic areas should be available at the end of october. [Contact: David L. Blackburn, (301) 975-2053]

\section{CEkER Calendar}

February 10-12 (San Diego, CA)

IEESE Semiconductor Thermal and Temperature Measurement symposium. This fourth annual SEMI-THERM symposium is sponsored by the Components, Hybrids, and Manufacturing technology Society of IEEE in cooperation with NBS and constitutes an international forum for the presentation of new developments in, and applications relating to, generation and removal of heat within semiconductor devices and measurement of junction temperatures experienced in various applications and environments. Major SEMI-THERM topic areas include thermal measurements, thermal characterization, applications, and computations and software.

The program includes keynote speakers, technical presentations, tutorial sessions, workshops, and an exhibit. In addition, the semiconductor Equipment and Materials Institute has scheduled in conjunction with SEMI-THERM a meeting of its Thermal Measurements Task Force, to which attendees are invited. [Contact: Frank F. Oettinger, (301) 975-2054] 
1988 Calendar (cont'd.)

May 11-13 (Los Angeles, CA)

Intersociety Conference on Thermal Phenomena in Fabrication and operation of Rlectronic components. This conference is sponsored by the Components, Hybrids, and Manufacturing Technology Society of the IEEE, in cooperation with ASME Committee $\mathrm{K}-16$ on Heat Transfer and NBS。 It is intended to provide an interdisciplinary forum for exploring the progress made in understanding, analyzing, and modeling thermal transport processes and thermally induced failures in the fabrication, assembly, and use of logic, memory, and datastorage systems. Major topic areas covered are 1) processing and fabrication, including state-of-the-art semiconductor crystal growing techniques; thermal stress in wafers, chips, substrates, PC boards, and joints; and encapsulant behavior with respect to solidification, outgassing, mechanical properties, and water vapor diffusion and absorption; 2) packaging technology, including means for cooling components from cryogenic to high temperatures and reliability as affected by failure mechanisms such as dopant migration and intermetallic growth; and 3) peripheral equipment, including data storage in both magnetic and optical media and thermal issues in dot-matrix and thermal printer heads. The conference is being held in conjunction with the Electronics Components Conference (May 9-11) at the same site. [Contact: Frank F. Dettinger, (301) 975-2054]

\section{Planned}

Early summer (Vail, Co)

Combined Short Course on Optical Fiber and Laser Measurements. [Contact: Aaron A. Sanders, (303) 497-5341]

Early fall (Boulder, CO)

Fiber optics symposium. [Contact: Aaron A. Sanders, (303) 497-5341]
Late fall (Boulder, Co)

Symposium on Optical Materials for High Power Lasers ( 20 th Boulder Damage Symposium). [Contact: Aaron A. Sanders, (303) 497-5341]

\section{CEIETE SPONSORS}

National Bureau of Standards

Department of Defense

Defense Nuclear Agency; Defense

Advanced Research Projects Agency;

National Security Agency;

Combined Army/Navy/Air Force

Calibration Coordination Group

U.S. Air Force

Newark Air Force Station; Rome Air

Development; Space \& Missile

Organization; Hanscom Air Force Base;

Wright-Patterson Air Force Base

U.S. Army

Aviation System Command; Fort

Belvoir; Fort Monmouth; Harry Diamond Laboratories; Materials \& Mechanics

Research; Strategic Defense Command

U.S. Navy

Naval Surface Weapons Center; Naval Ocean Systems Center; Naval Ordnance Systems Command; Naval Air Test

Center; Ordnance Disposal Technology Center; Weapons Support Center/Crane; office of Naval Research; Naval Air Engineering Center

Department of Energy

Energy Systems Research; Fusion

Energy; High Energy \& Nuclear

Physics; Bonneville Power

Administration

Department of Justice

Law Enforcement Assistance

Administration

Nuclear Regulatory Agency

Department of Treasury

Bureau of Engraving and Printing

Department of Transportation

National Highway Traffic Safety

The Charles Stark Draper Laboratory

International Copper Research

Association

Sandia National Laboratories

University of California

Los Alamos Scientific Laboratory 
1. PUBLICATION OR REPORT NO.

NBSIR $87-3655$
2. Performing Organ. Report Nod 3. Publication Date

October 1987
BIBLIOGRAPHIC DATA

SHEET (See in structions)

4. TITLE AND SUBTITLE

Center for Electronics and Electrical Engineering Technical Publication Announcements Covering Center Programs, January-March 1987, with 1987 CEEE Events Calendar

5. $\operatorname{AUTHOR}(S)$

E. Jane Walters, compiler

6. PERFORMING ORGANIZATION (If joint or other than NBS, see instructions)

7. ContractGrant No.

\section{NATIONAL BUREAU OF STANDARDS \\ U.S. DEPARTMENT OF COMMERCE \\ GAITHERSBURG, MD 20899}

8. Type of Report \& Period Covered

January-March 1987

9. SPONSORING ORGANIZATION NAME AND COMPLETE ADDRESS (Streeq, City, Stote, ZIP)

U.S. Department of Commerce

National Bureau of Standards

National Engineering Laboratory

Center for Electronics and Electrical Engineering

\section{SUPPLEMENTARY NOTES}

All technical information included in this document has been previously approved for publication.

$\square$ Document describes a computer program; SF-185, FIPS Software Summary, is attached.

11. ABSTRACT (A 200-word or less factual summary of most significont informotion. If document includes a significant bibliogrophy or literoture survey. mention it here)

This is the twelfth issue of a quarterly publication providing information on the technical work of the National Bureau of Standards Center for Electronics and Electrical Engineering. This issue of the Center for Electronics and Electrical Engineering Technical Publication Announcements covers the first quarter of calendar year 1987. Abstracts are provided by technical area for papers published this quarter.

12. KEY WORDS (Six to twelve entries; alphabetical order: capitalize only proper names; and seporate key words by semicolons) antennas; electrical engineering; electrical power; electromagnetic interference; electronics; instrumentation; laser; magnetics; microwave; optical fibers; semiconductors; superconductors

13. AVAILABILITY

$\mathrm{x}$ Unlimited

$\square$ For Official Distribution. Do Not Release to NTIS

Order From Superintendent of Documents, U.S. Government Printing Office, Washington, D.C. 20402.

[X] Order From National Technical Information Service (NTIS), Springfield, VA. 2216!

14. NO. OF PRINTED PAGES

21

15. Price 
$-$ 



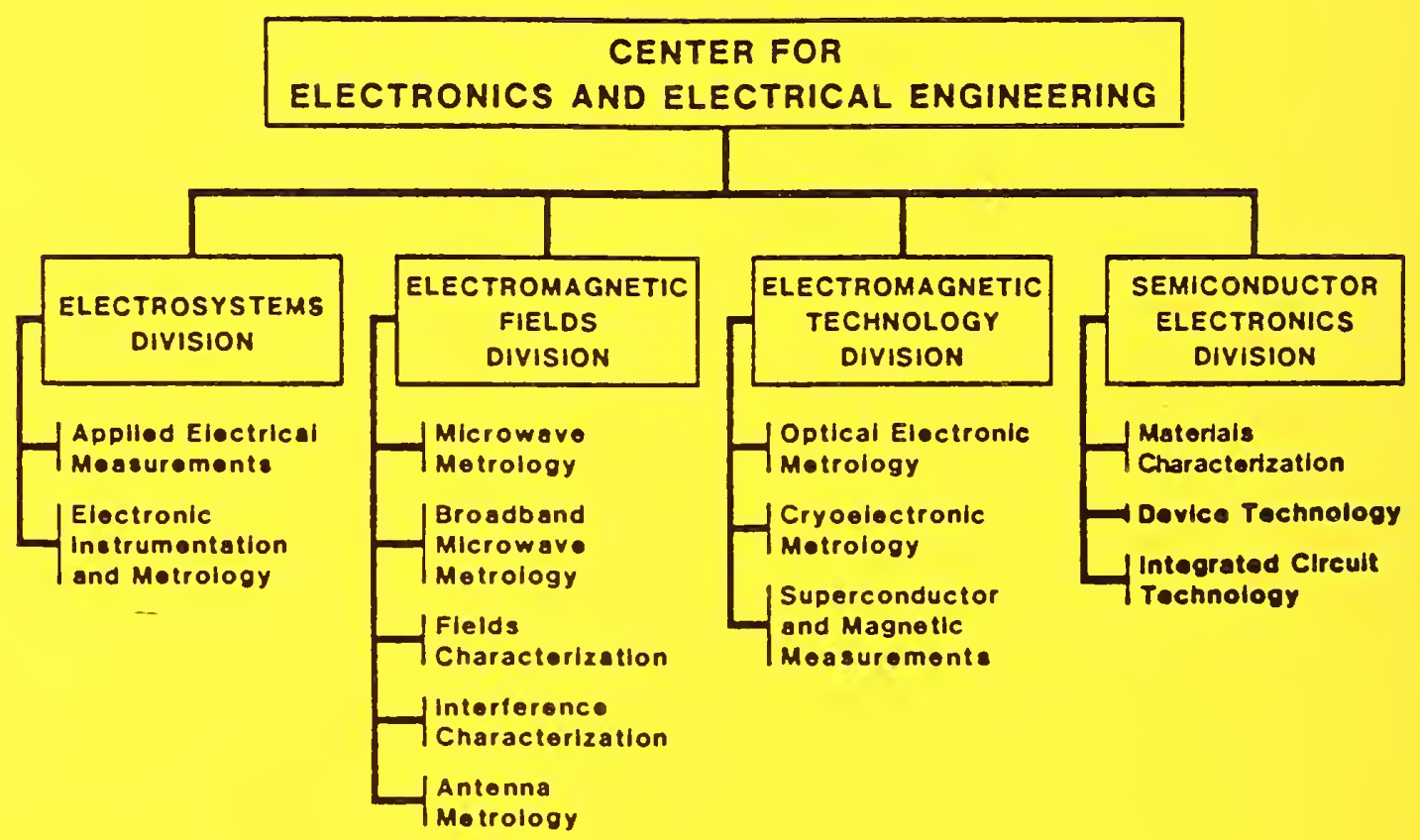

KEY CONTACTS:

Center Headquarters

$(720)$

Electrosystems Division (722)

Electromagnetic Fleids Division (723)

Electromagnetic Technology Division (724)

Semiconductor Electronics Division (727)

INFORMATION:

For additional Information on the Center for Electronics and Electrical Engineering, write or call:

Director, Mr. Judson C. French (301) 975-2220 Deputy DIrector, Mr. Robert I. Scace (301) 975-2220

Chlef, Dr. Oskars Petersons (301) 975-2400 Chlef, Dr. Ramon C. Baird (303) 497-3131 Chlef, Dr. Robert A. Kamper (303) 497-3535 Chlef, Mr. Frank F. Oettlnger (301) 975-2054 Center for Electronics and Electrlcal Englneering National Bureau of Standards Metrology Bullding, Room B-358 Galthersburg, MD 20898

Telephone (301) 975-2220 